\title{
X-Ray Absorption Spectral Studies on the Anion-Selectivity of a Ruthenium(II) Polypyridine Complex-Impregnated Polymer Ultrathin Film
}

\author{
Shuji Matsuo, ${ }^{* \dagger}$ Sunao Yamada, ${ }^{* *}$ Taku Matsuo,* and Hisanobu WaKITA*,*** \\ *Advanced Materials Institute, Fukuoka University, Nanakuma, Jonan, Fukuoka 814-0180, Japan \\ **Department of Materials Physics and Chemistry, Kyushu University, \\ Hakozaki, Higashi, Fukuoka 812-8581, Japan \\ ***Department of Chemistry, Faculty of Science, Fukuoka University, \\ Nanakuma, Jonan, Fukuoka 814-0180, Japan
}

\begin{abstract}
The anion-selectivity of the surface of a polymer ultrathin film incorporating an amphiphilic ruthenium(II) polypyridine complex with diperchlorate was examined using X-ray absorption spectroscopy with the total electron-yield method. The adsorbed species on the film surface were found to depend on the chemical composition in water where the film was prepared. By combining the X-ray absorption spectra with a molecular-orbital calculation, the molar ratio $\left(M_{\mathrm{ClO} 4} / M_{\mathrm{Ru}}\right)$ between the $\mathrm{ClO}_{4}^{-}$ions and the $\mathrm{Ru}$ head group on the film surface could be semi-quantitatively analyzed; it was 0.88 for a film prepared on fresh water, and 1.4 for one prepared on old water.
\end{abstract}

(Received August 9, 2001; Accepted April 19, 2002)

\section{Introduction}

An ultrathin polymer film incorporating an amphiphilic ruthenium(II) polypyridine complex (RuBP, which includes two perchlorate $\left(\mathrm{ClO}_{4}^{-}\right)$ions as a counter anion), prepared by a casting-on-water method, ${ }^{1}$ has been used for studies of optical second-harmonic generation, consequently showing that the ruthenium complex molecules preferentially align on a single surface of a film. ${ }^{2-4}$

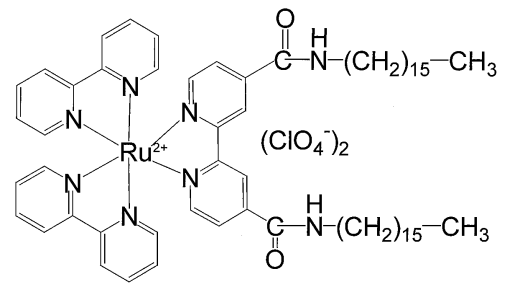

RuBP (illustrated as $\bullet$ in Scheme 1)

So far, we have performed X-ray absorption spectroscopy (XAS) experiments using the total electron yield (TEY) method for various RuBP-impregnated polymer thin films prepared for examining the chemical states of a ruthenium complex on the film surface. ${ }^{5}$ As a result, $\mathrm{Ru} \mathrm{L}$ - and $\mathrm{Cl}$ K-edge X-ray absorption near-edge structure (XANES) spectra, which were

\footnotetext{
† To whom correspondence should be addressed.

E-mail:mashu23@hotmail.com

This paper is a part of the proceedings of IUPAC International Congress on Analytical Sciences, Vol. 17 special issue of this journal.
}

obtained by the total electron yield using a photomultiplier, showed that the electrons emitted by the X-ray absorption cannot pass through a polymer film with a thickness of 50-70 $\mathrm{nm}$ (by atomic force microscopy ${ }^{1}$ ). It was thus found that the observed $\mathrm{Ru} \mathrm{L}$ - and $\mathrm{Cl}$ K-edge XANES spectra provide exclusive information about the surface of RuBP-impregnated polymer thin films upon which X-rays are directly irradiated. Exclusive information means information about the $\mathrm{Ru}$ head group and $\mathrm{ClO}_{4}^{-}$ions on the film surface. In addition, it showed an interesting phenomenon: that the intensity ratio between the peaks of the $\mathrm{Ru} \mathrm{L}$ - and $\mathrm{Cl} \mathrm{K}$-edge on the XANES spectra is strongly affected by the differences in the preparation conditions of the RuBP-impregnated polymer thin films. This result suggests affording an anion-selectivity to the RuBPimpregnated polymer thin film.

In this paper, we discuss the anion-selectivity of an RuBPimpregnated polymer thin film based on the XANES spectra, and also consider the development toward a semi-quantitative analysis of the film surface based on the XANES spectra and a theoretical molecular orbital calculation.

\section{Experimental}

The X-ray absorption spectra were measured at BL7A of the UVSOR at the Institute of Molecular Science, Okazaki. ${ }^{6}$ The ring energy of the UVSOR storage ring was $750 \mathrm{MeV}$ and the stored current was 110-230 mA. Ru L- and $\mathrm{Cl}$ K-edge absorption spectra were recorded in the region of $2800-3000$ $\mathrm{eV}$ using two $\mathrm{Ge}(111)$ crystals, while $\mathrm{Br}$ L-edge absorption spectra were recorded in the region of $1550-1700 \mathrm{eV}$ using two KTP $(011)$ crystals. The absorption was monitored by the total electron yield using a photomultiplier.

An RuBP solution and an RuBP-impregnated polymer thin 


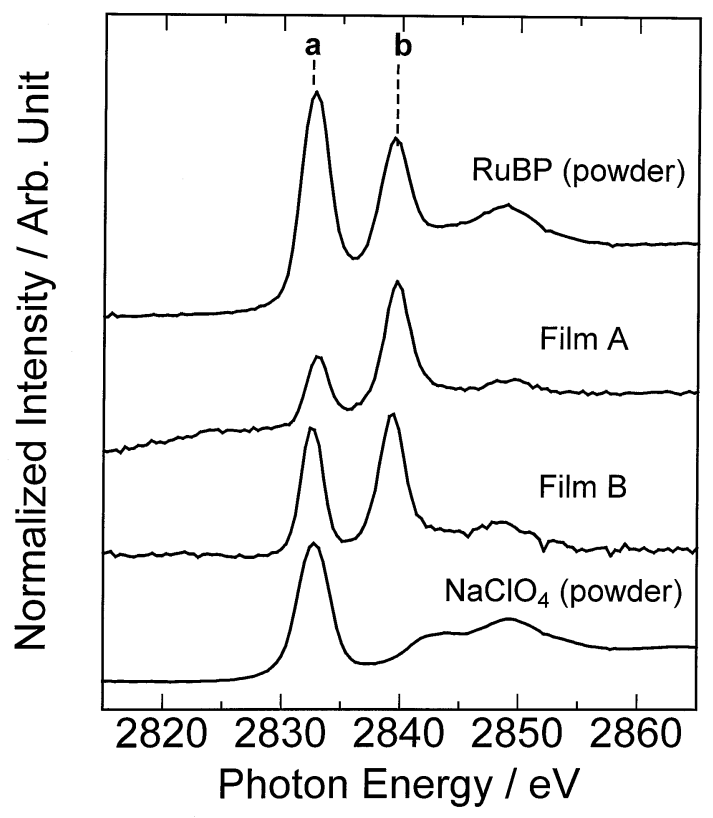

Fig. 1 XANES spectra of RuBP powder, two RuBP-impregnated PMMA thin films prepared under different conditions ( $\mathrm{A}$ and $\mathrm{B}$ ), and $\mathrm{NaClO}_{4}$ powder. Peaks a and $\mathrm{b}$ were derived from the $\mathrm{ClO}_{4}{ }^{-}$ion and $\mathrm{Ru}$ head group, respectively.

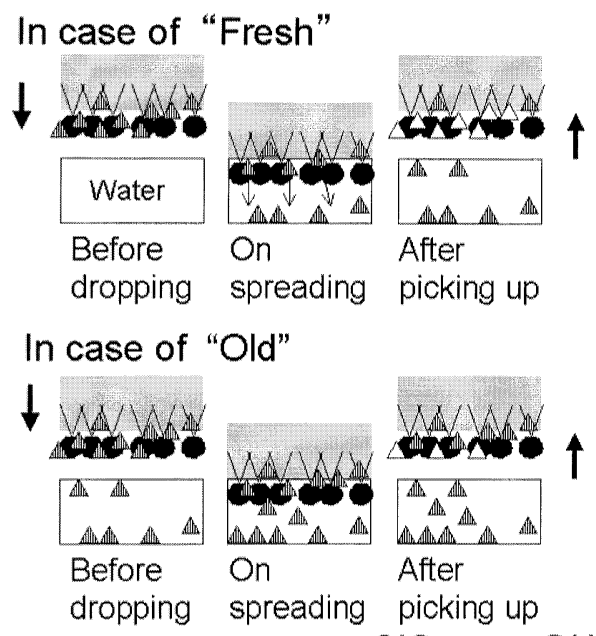

$$
\mathbb{A}: \mathrm{ClO}_{4}^{-} \triangle: \mathrm{OH}^{-}
$$

Scheme 1 Schematic explanation of the variation of the $I_{\mathrm{a}} / I_{\mathrm{b}}$-values for films A and B in Fig. 1. The details are described in the text.

film were prepared by procedures described elsewhere. ${ }^{1,5,7}$ Here, poly(methyl methacrylate) (PMMA) was applied as a polymer material. In order to examine the anion-selectivity of the RuBP-impregnated PMMA thin film, the film was prepared on the surface of water to which was added in advance several anions $\left(\mathrm{ClO}_{4}^{-}, \mathrm{Cl}^{-}\right.$, and $\left.\mathrm{Br}^{-}\right)$. These anions were added as sodium salt and the molar quantity of these anions was 50000times that of normally dropping the RuBP solution on the water surface.

The profiles of the observed XANES spectra were reproduced theoretically by discrete variational $\mathrm{X} \alpha(\mathrm{DV}-\mathrm{X} \alpha)$ calculations. ${ }^{8}$ The calculated models and conditions were as follows. $\left[\mathrm{Ru}(\mathrm{bpy})_{3}\right]^{2+}$ model: the model structure is surrounded by six $\mathrm{ClO}_{4}^{-}$ions based on the crystal structure from Ref. 9.

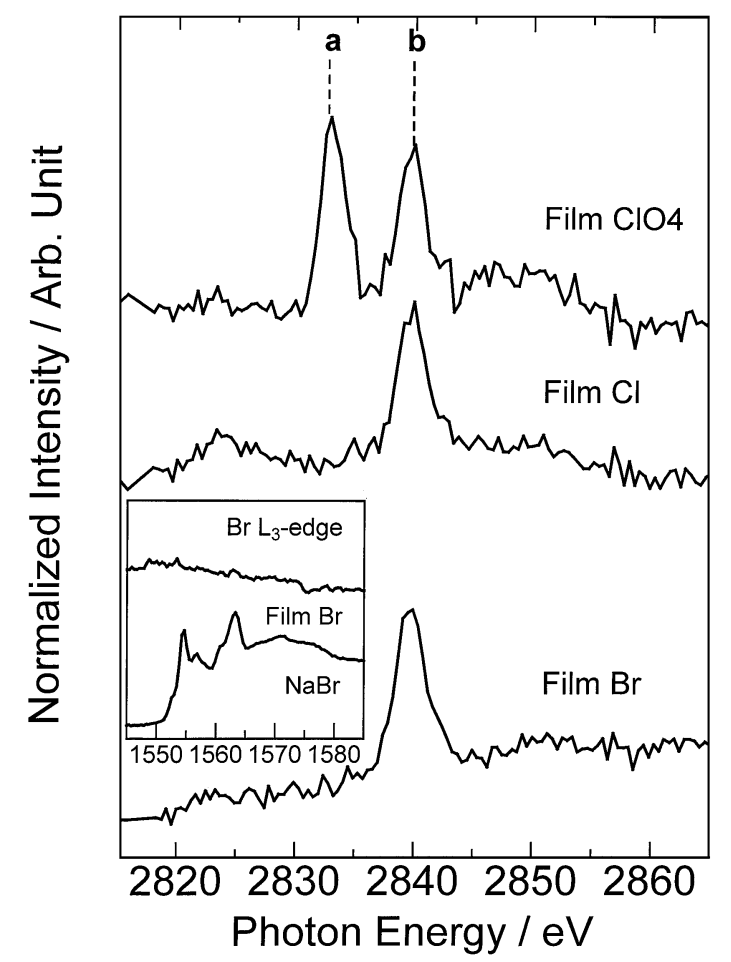

Fig. 2 Effect of an adsorbed anion on an RuBP-impregnated PMMA thin film surface upon the profiles of the XANES spectra of the films. The peak notations are the same as those in Fig. 1. The inset shows $\mathrm{Br} \mathrm{L}_{3}$-edge XANES of the film with $\mathrm{Br}$ and $\mathrm{NaBr}$ powder as a reference.

Numerical atomic orbitals were used as a basis set for DV-X $\alpha$ calculations: 1 s to $6 \mathrm{~d}$ for $\mathrm{Ru}, 1 \mathrm{~s}$ to $3 \mathrm{p}$ for $\mathrm{N}, 1 \mathrm{~s}$ to $2 \mathrm{p}$ for $\mathrm{C}$ and $\mathrm{O}, 1 \mathrm{~s}$ to $3 \mathrm{~d}$ for $\mathrm{Cl}$, and $1 \mathrm{~s}$ for $\mathrm{H}$. The sample points used in the numerical integration were taken up to 33500 . Self-consistency within 0.001 electron was obtained for the final orbital populations. $\mathrm{ClO}_{4}^{-}$model: the model structure consists of five $\mathrm{ClO}_{4^{-}}$ions based on the crystal structure from Ref. 10. Numerical atomic orbitals were used as a basis set for DV-X $\alpha$ calculations: 1 s to $4 \mathrm{p}$ for $\mathrm{Cl}$ and $1 \mathrm{~s}$ to $3 \mathrm{p}$ for $\mathrm{O}$. The sample points used in the numerical integration were taken up to 25000 . Self-consistency within 0.001 electron was obtained for the final orbital populations.

\section{Results and Discussion}

The XANES spectra of RuBP powder, an RuBP film prepared on fresh water (denoted as film A), an RuBP film prepared on old water (denoted as film $\mathrm{B}$ ), and $\mathrm{NaClO}_{4}$ powder are shown in Fig. 1. Each peak of the XANES spectra was assigned experimentally in our previous work; ${ }^{5}$ peak a is the $\mathrm{Cl} \mathrm{K}$-edge absorption of $\mathrm{NaClO}_{4}$ and peak $\mathrm{b}$ is the $\mathrm{Ru} \mathrm{L}_{3}$-edge absorption of the $\mathrm{Ru}(\mathrm{bpy})_{3}$-like moiety in RuBP. The difference in the intensity ratio $\left(I_{\mathrm{a}} / I_{\mathrm{b}}\right)$ between peaks a and $\mathrm{b}$ of films $\mathrm{A}$ and B is due to a change in the preparation conditions of the RuBPimpregnated PMMA thin films. Films A and B were prepared by using "fresh" and "old" water, respectively. Here, "fresh" water is defined as a water surface on which the film preparation was performed for the first time, while "old" water is defined as a water surface on which the film preparation was repeated without refreshing. The variation in the $I_{\mathrm{a}} / I_{\mathrm{b}}$ values is explained by the change in the stoichiometric ratio between the 


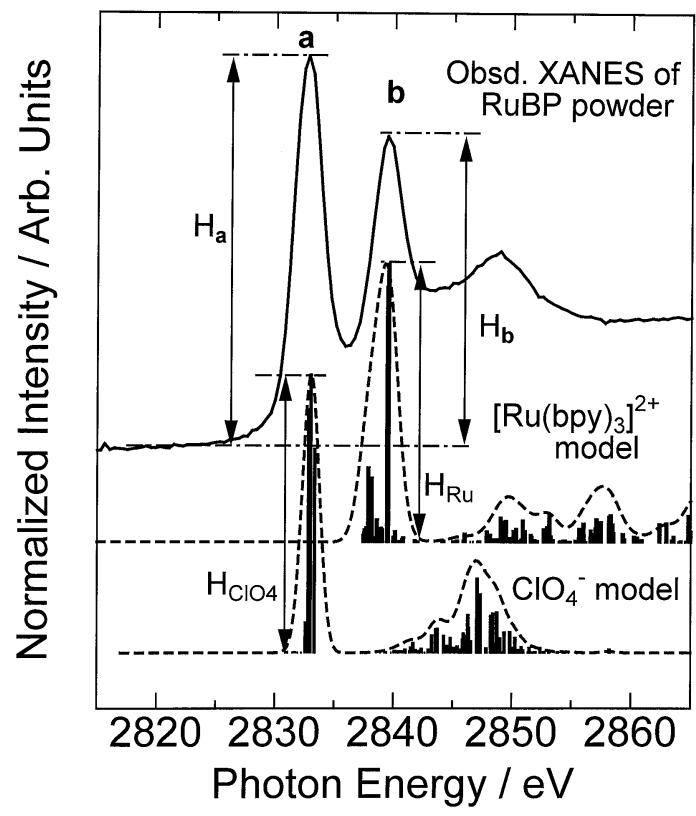

Fig. 3 Calculated transition probabilities (vertical bars) and peaks (broken lines) of $\left[\mathrm{Ru}(\mathrm{bpy})_{3}\right]^{2+}$ and $\mathrm{ClO}_{4}^{-}$models by the $\mathrm{DV}-\mathrm{X} \alpha$ method and the observed XANES spectrum of the RuBP powder (solid line). The peak heights $\left(H_{\mathrm{a}}, H_{\mathrm{b}}, H_{\mathrm{ClO} 4}\right.$, and $\left.H_{\mathrm{Ru}}\right)$ are indicated by arrows for each peak.

$\mathrm{Ru}$ head group and the counter ions on the film surface, and is illustrated in Scheme 1. In the beginning of film preparation, a 2:1 ratio between the $\mathrm{ClO}_{4}^{-}$ions and the $\mathrm{Ru}$ head group is strictly held in the RuBP solution. After the RuBP film spread on the water surface is subsequently picked up from the surface using a plastic framework, a part of the $\mathrm{ClO}_{4}{ }^{-}$ions might remain in the aqueous phase. As a consequence, the molar ratio of $\mathrm{ClO}_{4}{ }^{-}$ions with respect to the $\mathrm{Ru}$ head group at the film surface would become less than 2 . Then, the $I_{\mathrm{a}} / I_{\mathrm{b}}$-value must be considerably reduced when the thin film is formed on fresh water. This suggests that the absent counter charge caused by non-stoichiometric $\mathrm{ClO}_{4}^{-}$ion would be provided by the $\mathrm{OH}^{-}$ion. If the old water is repeatedly used in the film preparation, the leftover $\mathrm{ClO}_{4}{ }^{-}$ions would be enriched to the solvent-water interface. Therefore, the $I_{\mathrm{a}} / I_{\mathrm{b}}$ value for film $\mathrm{B}$ is naturally considered to be much larger than that for film A.

In order to verify this consideration, for an RuBP-impregnated PMMA thin film prepared on the surface of water added in advance, the excessive molar quantity of $\mathrm{ClO}_{4}^{-}$ion (denoted as film $\mathrm{ClO}_{4}$ ) was measured by XAS; the XANES spectrum is shown in Fig. 2. The $I_{\mathrm{a}} / I_{\mathrm{b}}$ value for film $\mathrm{ClO}_{4}$ is much larger than that for film B, and is close to that for the RuBP powder. The experimental result thus supports the above explanation. However, as can be seen in Fig. 2, concerning the XANES spectra of the RuBP-impregnated PMMA thin film prepared on the surface of water added in advance, for an excessive molar quantity of $\mathrm{Cl}^{-}$and $\mathrm{Br}^{-}$ions (denoted as film $\mathrm{Cl}$ and film $\mathrm{Br}$, respectively), no peak can be seen in the region $2830-2835 \mathrm{eV}$. From the results, it is expected that $\mathrm{ClO}_{4}{ }^{-}$ion on the film surface is exchanged for $\mathrm{Cl}^{-}$and/or $\mathrm{OH}^{-}$ions, and for $\mathrm{Br}^{-}$and/or $\mathrm{OH}^{-}$ ions, respectively. If the $\mathrm{ClO}_{4}^{-}$ion were preferentially exchanged for the $\mathrm{Cl}^{-}$or $\mathrm{Br}^{-}$ion, a large, sharp peak for the $\mathrm{Cl}^{-}$ or $\mathrm{Br}^{-}$ion would appear at $2824 \mathrm{eV}^{-}$for the $\mathrm{Cl}^{-}$ion ${ }^{5}$ or at 1555 $\mathrm{eV}$ for $\mathrm{Br}^{-}$in the XANES spectrum. Such a peak, however, does not appear in the XANES spectrum of the film with $\mathrm{Cl}$ or $\mathrm{Br}$. In other words, the $\mathrm{Cl}^{-}$or $\mathrm{Br}^{-}$ion was not selectively

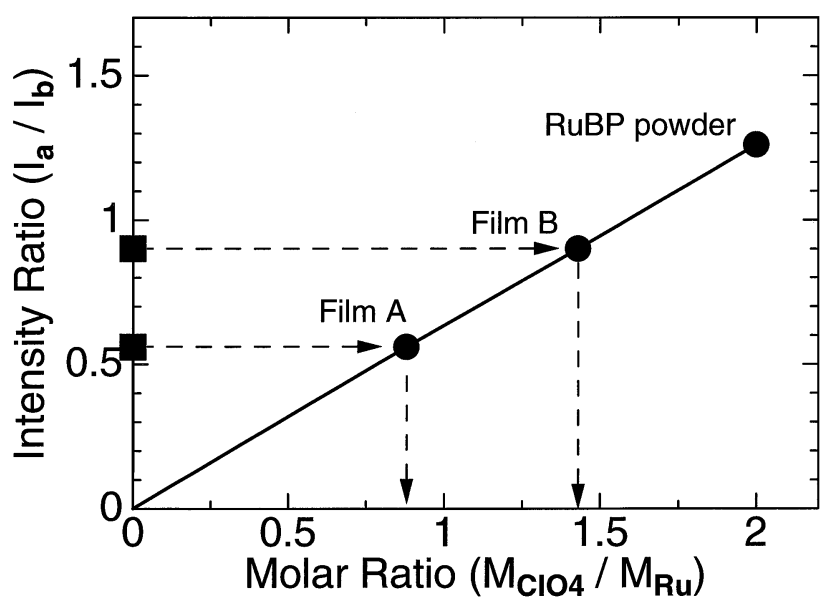

Fig. 4 Semi-quantitative analysis for an RuBP-impregnated PMMA thin film surface from a correlation of the intensity ratio $\left(I_{\mathrm{a}} / I_{\mathrm{b}}\right)$ and molar ratio $\left(M_{\mathrm{ClO} 4} / M_{\mathrm{Ru}}\right)$.

adsorbed on the film surface. In the case of the film with $\mathrm{Cl}$ or $\mathrm{Br}$, it is eventually suggested that the $\mathrm{ClO}_{4}^{-}$ion is preferentially exchanged for the $\mathrm{OH}^{-}$ion because the $\mathrm{ClO}_{4}^{-}$ion may form an ion pair with an excessive counter cation, $\mathrm{Na}^{+}$, dissolved in water, but is not enriched at the solvent-water interface.

The theoretical XANES spectra of $\left[\mathrm{Ru}(\mathrm{bpy})_{3}\right]^{2+}$ and $\mathrm{ClO}_{4}^{-}$ models calculated by the DV-X $\alpha$ method are shown along with the observed XANES spectrum of the RuBP powder in Fig. 3, where the bars indicate the electronic transition probabilities from $\mathrm{Ru}$ or $\mathrm{Cl} 1 \mathrm{~s}$ to the upper empty orbitals; the broken lines show theoretical XANES spectra convoluted from the bars by a Gaussian function with a half width at half-maximum of $1.0 \mathrm{eV}$. The observed XANES spectrum of the RuBP powder is seen to be theoretically reproduced by superposing the calculated curve for the $\left[\mathrm{Ru}(\mathrm{bpy})_{3}\right]^{2+}$ model on the calculated curve for the $\mathrm{ClO}_{4}^{-}$ model. Thus, the peak feature at $2849 \mathrm{eV}$ of the observed XANES spectrum of the RuBP powder is found to be mostly composed of the transition peak of the $\mathrm{ClO}_{4}^{-}$ion.

Such an attempt to superpose two calculated curves would enable us to estimate the $I_{\mathrm{a}}: I_{\mathrm{b}}$ ratio by fitting the intensity of the calculated peak to that of the observed peak. For example, when the calculated peak heights $\left(\mathrm{H}_{\mathrm{ClO} 4}\right.$ and $\left.\mathrm{H}_{\mathrm{Ru}}\right)$ of the $\mathrm{ClO}_{4}^{-}$ and $\left[\mathrm{Ru}(\mathrm{bpy})_{3}\right]^{2+}$ models are allowed to correspond to the heights $\left(H_{\mathrm{a}}\right.$ and $\left.H_{\mathrm{b}}\right)$ of peaks a and $\mathrm{b}$ of the observed XANES spectrum for RuBP powder, respectively (see Fig. 3), $H_{\mathrm{ClO} 4}$ and $H_{\mathrm{Ru}}$ become 1.4-times and 1.1-times those of the original peak heights, respectively. Also, when these values are defined as the intensities of peaks $a$ and $b$ of the observed XANES spectrum for RuBP powder, respectively, the obtained $I_{\mathrm{a}} / I_{\mathrm{b}}$ value is 1.3 . This value can be converted to the molar ratio $\left(M_{\mathrm{ClO} 4} / M_{\mathrm{Ru}}\right)$ between the $\mathrm{ClO}_{4}^{-}$ions and the $\mathrm{Ru}$ head group on the RuBP powder as 2, because the 2:1 ratio between the $\mathrm{ClO}_{4}^{-}$ ions and the $\mathrm{Ru}$ head group is strictly held in RuBP powder. This $I_{\mathrm{a}} / I_{\mathrm{b}}$ value was plotted using a molar ratio of 2 ; a calibration curve was obtained from this plot point and zero point. The correlation between the $I_{\mathrm{a}} / I_{\mathrm{b}}$ and $M_{\mathrm{ClO} 4} / M_{\mathrm{Ru}}$ values is shown in Fig. 4. The $I_{\mathrm{a}} / I_{\mathrm{b}}$ values for RuBP-impregnated PMMA thin films can be estimated in a similar manner ( 0.56 and 0.90 for films A and B, respectively). They are shown as $\boldsymbol{n}$ in Fig. 4. Finally, the $M_{\mathrm{ClO} 4} / M_{\mathrm{Ru}}$ values could be semi-quantitatively obtained by an interpolation of Fig. 4 (shown as •); that of film A is 0.88 , while that of film B is 1.4 .

In conclusion, by monitoring a RuBP-impregnated PMMA 
thin film using the XAS method, the ion-selectivity and charge of adsorbed species on the surface were easily investigated, and the adsorbed species could be semi-quantitatively analyzed in combination with DV-X $\alpha$ molecular-orbital calculations.

\section{Acknowledgements}

This work was supported by the Joint Studies Program (2000 2001) of the Institute for Molecular Science and the Advanced Materials Institute of Fukuoka University.

\section{References}

1. S. Yamada, Y. Tanaka, M. Kawazu, and T. Matsuo, Supramol. Sci., 1998, 5, 379.

2. T. Matsuo, H. Nakamura, T. Nakao, and M. Kawazu,
Chem. Lett., 1992, 2363.

3. S. Yamada, T. Nakano, and T. Matsuo, Thin Solid Films, 1994, 245, 196.

4. T. Nakano, Y. Yamada, T. Matsuo, and S. Yamada, J. Phys. Chem. B, 1998, 102, 8569.

5. S. Matsuo, T. Nakano, S. Yamada, T. Matsuo, and H. Wakita, J. Electron Spectrosc. Relat. Phenom., 2001, 113, 193.

6. T. Murata, T. Matsukawa, S. Naoè, T. Horigome, O. Matsuodo, and M. Watanabe, Rev. Sci. Instrum., 1992, 63, 1309.

7. T. Matsuo, K. Tanaka, Y. Tsutsui, and T. Nishijima, J. Coord. Chem., 1980, 10, 187.

8. H. Adachi, M. Tsukada, and C. Satoko, J. Phys. Soc. Jpn., 1978, 45, 875 .

9. E. Krausz, H. Riesen, and A. D. Rae, Aust. J. Chem., 1995, $48,929$.

10. R. Wartchow and H. J. Berthold, Z. Kristallogr., 1978, 147. 